\title{
Analysis of a summer smog episode in the Berlin-Brandenburg region with a nested atmosphere - chemistry model
}

\author{
S. E. Bauer and B. Langmann \\ Max Planck Institute for Meteorology, Hamburg, Germany \\ Received: 6 March 2002 - Published in Atmos. Chem. Phys. Discuss.: 20 June 2002 \\ Revised: 16 September 2002 - Accepted: 17 October 2002 - Published: 27 October 2002
}

\begin{abstract}
An analysis of a pollution episode in an urban atmosphere, using a complex model system is presented. The nested atmosphere-chemistry model system simulates the atmospheric conditions during a one week measurement campaign, called FLUMOB, in July 1994 in Berlin-Brandenburg, Germany. The analysis shows that naturally emitted hydrocarbons played the dominant role in the ozone formation in the investigated area. The composition of non-methane volatile organic compounds was made up to $70-80 \%$ by biogenically emitted hydrocarbons. During the analysed case, ozone formation was sensitive to hydrocarbon concentrations so that the ozone production was limited by the availability of hydrocarbons and thus especially by the amount which was biogenically emitted. Furthermore, it is shown that the FLUMOB episode was influenced by elevated concentrations of ozone in the free troposphere. In contrast to previous analyses, the importance of ozone produced outside of Europe is emphasized. In spite of the stagnant high pressure situation which occurred during the FLUMOB episode Germany was significantly influenced by long-range transport of ozone. This transport also influenced near surface ozone concentrations.
\end{abstract}

\section{Introduction}

The changing atmosphere rises air quality as one of the prominent environmental issues of the last and the current century. It is increasingly recognized that changes in the emissions of chemicals associated with evolving land-use (including agricultural practices, biomass burning) and industrial development (including urbanization and transportation) are becoming major causes of global changes in the Earth system. The formation rate of tropospheric ozone has been enhanced by changes in the atmospheric composition.

Correspondence to: S. E. Bauer (bauer@1sce.saclay.cea.fr)
Globally, the industrial development leads to enhanced release of nitrogen oxides, carbon monoxide and a variety of hydrocarbons from fossil fuel and biomass burning. Although, that some Western countries have been reduced these emissions. It is important to analyse natural and anthropogenic air pollutant precursors to create effective emission control strategies. In case of the photochemical smog, peak ozone concentrations seem to have decreased during the last years but the background ozone level has increased. An annual increase of $1-2 \%$ in Europe has been observed in the past 30 years (Seinfeld and Pandis, 1998). The observed increasing amounts of background ozone demonstrate that air pollution is not limited to the regional scale. From the global point of view it is important to analyse the impact of regional ozone formation on the global tropospheric ozone budget and thus on changes on the oxidizing capacity of the troposphere.

In this paper, the polluted urban atmosphere in BerlinBrandenburg, Germany is investigated. Berlin was chosen because it represents atmospheric conditions of a German city and thus differs substantially from other intensively investigated smog regions, e.g. Los Angeles, Athens or Mexico D.F. due to its climatic conditions and the composition of emissions. In Germany summer smog events occur episodically, strongly dependent on the weather conditions. In comparison to the above mentioned megacities Berlin is not a 'smog-city'. However, Berlin was chosen for this investigation because it is located in a rural environment. Therefore it is expected that the transport and transformation of urban air pollution caused by the city of Berlin can be easily analysed. The observational data sets used for this study are monitored during the summer smog field experiment FLUMOB (Airborne and station observation of ozone and its precursor to estimate the efficiency of emission control strategies for ozone reduction in the area of Berlin-Brandenburg) (Stark et al., 1995).

The data sets of this field experiment have been already used to evaluate the applied atmosphere-chemistry model 
system. Bauer and Langmann (2002) describe the model system and the statistical evaluation in detail. The most important results of this evaluation can be summarized as follows:

- The meteorological simulation of the model is of high quality. A homogeneous weather condition (a quasistationary high-pressure system over central Europe) and the flat topography in the area of Brandenburg lead to simple meteorological condition that are very useful to enable the analysis of the chemical simulation.

- The simulation of the nitrogen dioxide concentrations correlates very well with the observations. This indicates the high quality of the anthropogenic emission data sets.

- The near surface ozone simulation is of excellent quality in the urban region but the model tends to underpredict ozon in the rural environment.

- In the upper boundary layer and in the free troposphere ozone is systematically underpredicted.

The emphasize of the current paper is to analyse these model discrepancies and furthermore to give more insight in the summer smog event monitored during FLUMOB. A short model description is given in the following section. Section 3 introduces the FLUMOB episode. The process of local ozone formation is studied by analysing the $\mathrm{VOC} / \mathrm{NO}_{\mathrm{x}}$ regimes in Sect. 4. The larger regional scale conditions and their impact on the GESIMA simulation are analysed in Sect. 5. Final conclusion are drawn in Sect. 6.

\section{Model description}

Model results of the atmosphere-chemistry model GESIMA (Geesthacht Simulation Model of the Atmosphere) are presented in this paper. GESIMA is part of a mesoscale model chain that consists of two Eulerian models (REMO and GESIMA) that are applied in three different resolutions. To address the scientific questions central to the FLUMOB measurement campaign the simulation domains of the models are chosen to focus down from the wider European domain to a narrower area of Germany and then to the even narrower area of Berlin-Brandenburg. The regional atmosphere-chemistry model REMO is applied with a horizontal grid point resolution of $0.5^{\circ}(\approx 50 \mathrm{~km})$ over Europe and with a $1 / 6^{\circ}$ resolution $(\approx 18 \mathrm{~km})$ covering Germany. GESIMA focus on the Berlin-Brandenburg region on a horizontal grid-point resolution of $4 \mathrm{~km}$. The model simulations are carried out one after the other, so that each finer simulations is embedded in the coarser simulation.

REMO is an hydrostatic three-dimensional atmospherechemistry model (Langmann, 2000). The dynamical part is based on the regional weather forecast model system EM (Europa Modell)/ DM (Deutschland Modell) of the German
Weather Service (Majewski, 1991). For the calculation of chemical transformations the RADM II gas-phase mechanism (Stockwell et al., 1990) and aqueous chemistry processes according to Walcek and Taylor (1986) are included. The REMO simulations are embedded into the meteorological fields of analysis data from the German Weather Service. The chemical concentrations of all prognostic species are set to constant values at the lateral boundaries of the coarse European-wide REMO simulation.

GESIMA is a non-hydrostatic atmosphere-chemistry model on the meso- $\gamma$ scale (Bauer and Langmann, 2002). For the calculation of chemical transformations the RADM II gas-phase mechanism is included. GESIMA is nested into the German wide REMO simulation by considering the following variables: horizontal wind velocities, temperature, specific humidity and trace species mixing ratios.

The models are integrated for the period 20-30 July 1994. A detailed model description of the models and the experiment set up is presented in Bauer and Langmann (2002).

\section{The FLUMOB episode}

The weather condition during the FLUMOB measurement episode was optimal for the photolytical production of ozone and other photooxidants because of high temperatures and strong solar irradiation. Due to the meteorological conditions the FLUMOB period in the Berlin-Brandenburg area can roughly be divided into two episodes. The first episode from 22 July until 25 July, was characterized by advected air masses coming from the south-east. Strong vertical mixing raised the planetary boundary layer height up to about $3000 \mathrm{~m}$ (Stark et al., 1995). During the following days the FLUMOB area was influenced by sub-tropical air masses coming from southern directions. In addition to high ozone concentrations high amounts of precursor gases were transported to the Berlin-Brandenburg area during the second episode. In the following the period from 22 July to 25 July 1994 will be denoted as episode I and the period between 25 July until the end of the measurement campaign, 28 July, will be named episode II.

Modeled near surface ozone concentrations during one day in episode I (Fig. 1) and episode II (Fig. 2) are presented. While ozone concentrations of about 40 to $70 \mathrm{ppb}_{\mathrm{v}}$ are reached during episode I ozone shows concentrations between 70 and $100 \mathrm{ppb}_{\mathrm{v}}$ in episode II. The spatial distribution of ozone differs strongly from day to day depending on the changing wind field, the transport of chemical species from outside into the Berlin-Brandenburg area and the local emissions. Because of the dominant role of local emissions on the process of pollutant formation in the lower troposphere they will be discussed in the following sub-section. 


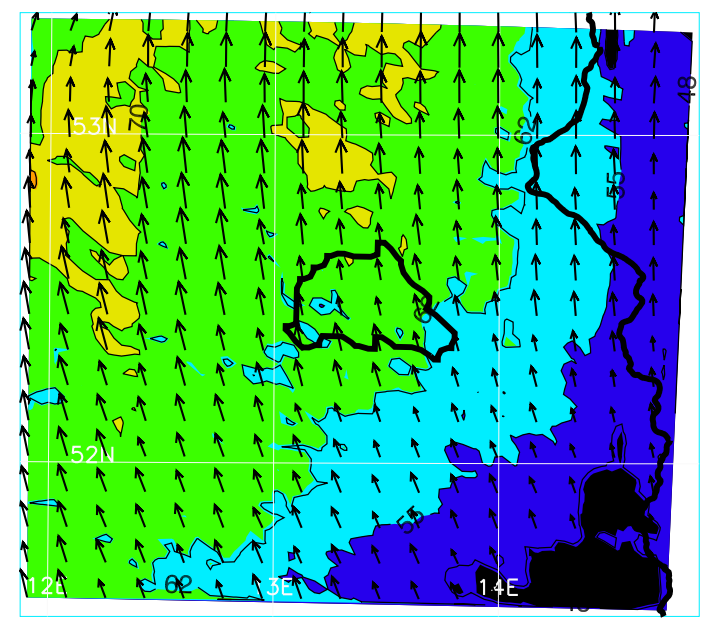

40. 48. 55. 62. 70. 78. 85. 92. 100. 108. 115

Fig. 1. Near surface ozone concentrations $\left(\mathrm{ppb}_{\mathrm{v}}\right)$ and wind directions on 23 July at 14:00 UTC in Berlin-Brandenburg. Berlin and the border to Poland are marked in black, latitudes and longitudes in white. The model results are projected to this map.

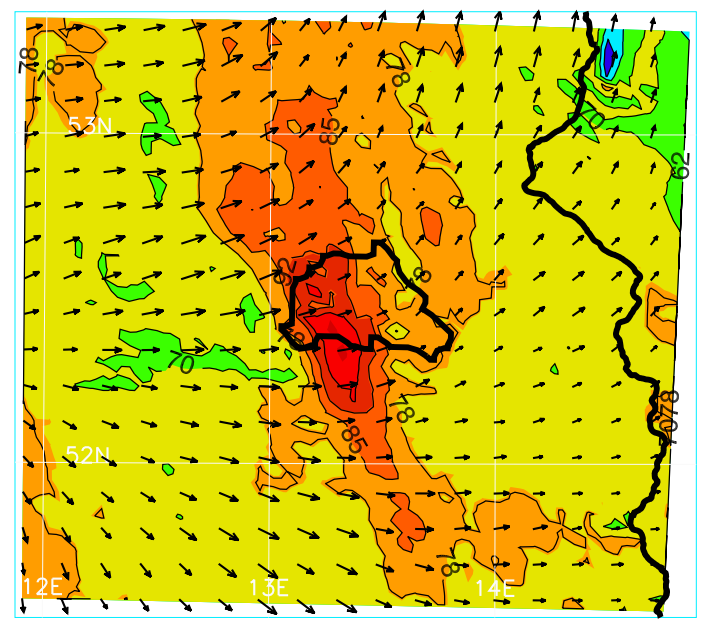

40. 48. 55. 62. 70. 78. 85. 92. 100. 108. 115.

Fig. 2. As Fig. 1, but on 26 July.

\subsection{Emissions}

\section{Anthropogenic Emissions}

The GESIMA emission inventory for the FLUMOB episode was prepared by the IER (Institut für Energiewirtschaft und Rationelle Energieanwendung) in Stuttgart (Friedrich et al., 2002). Each day was individually calculated. Examples for two classes of anthropogenic emissions are illustrated in the Figs. 3 to 6 . The horizontal distribution of the $\mathrm{NO}_{\mathrm{x}}$ emissions, the sum of $\mathrm{NO}$ and $\mathrm{NO}_{2}$, are shown exemplarily for

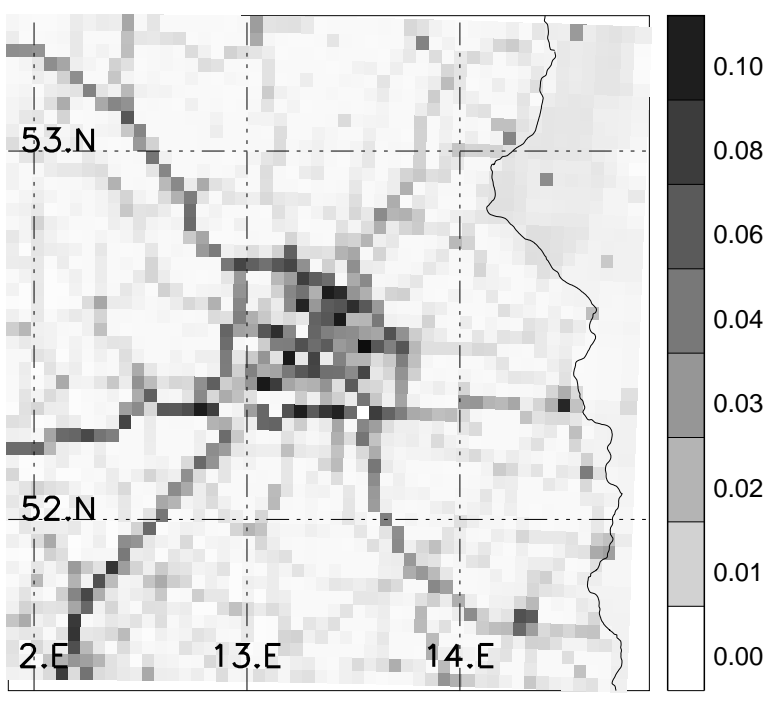

Fig. 3. $\mathrm{NO}_{\mathrm{x}}$ emission on 25 July 1994 at 06:00 UTC. The emissions are in units of $[\mathrm{t} / \mathrm{h}]$.
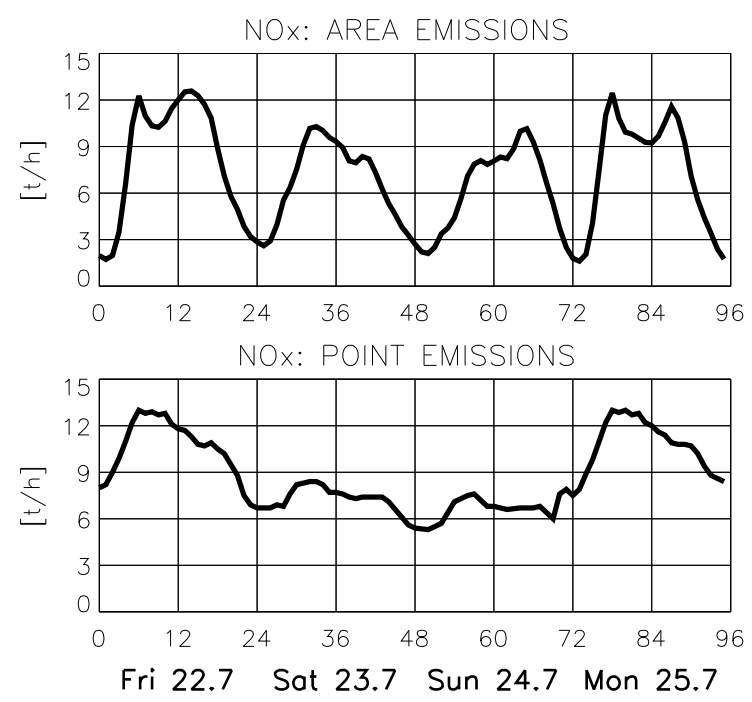

Fig. 4. Time series of $\mathrm{NO}_{\mathrm{x}}$ emission as sum of all area emission sources (upper panel) and point sources (lower panel) released into the domain between 22 and 25 July. The emissions are in units of [t/h].

25 July at 06:00 UTC in Fig. 3. The major $\mathrm{NO}_{\mathrm{x}}$ sources are traffic and industrial acitivities emitting predominantly in the city of Berlin and the frequently used highways. The curves in Fig. 4 show the time evolution of the total area (upper panel) and point (lower panel) $\mathrm{NO}_{\mathrm{x}}$ emissions for 4 days (Friday to Monday) of the FLUMOB episode. Different time evolutions between weekday and weekend emission are visible. The total amount of point and area emissions for $\mathrm{NO}_{\mathrm{x}}$ is in about the same range. During weekdays the $\mathrm{NO}_{\mathrm{x}}$ 


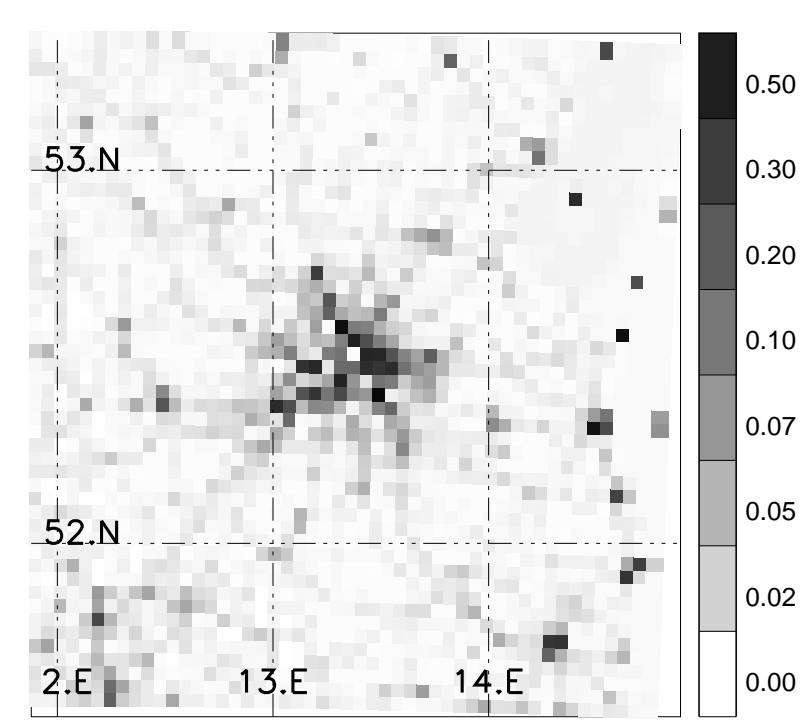

Fig. 5. Anthropogenic VOC emissions on 25 July at 06:00 UTC. The emissions are in units of $[\mathrm{t} / \mathrm{h}]$.
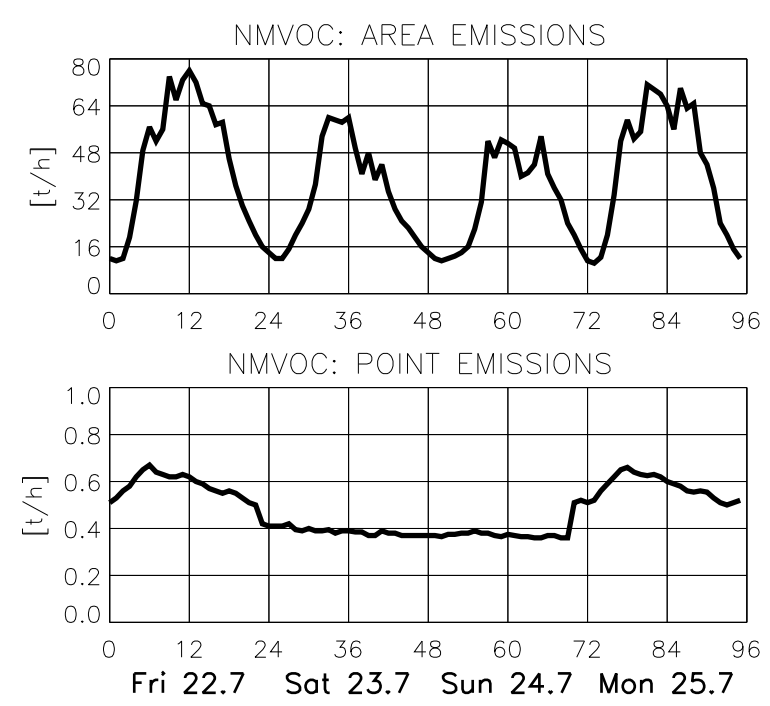

Fig. 6. Time series of VOC emission as sum of all area emission sources (upper panel) and point sources (lower panel) released into the domain between 22 and 25 July. The emissions are in units of $[\mathrm{t} / \mathrm{h}]$.

emissions show a daily double peak structure, indicating the morning and evening rush hours.

All anthropogenic non-methane volatile organic compound (VOC) emissions are summed up and presented in Fig. 5. The dominant VOC source is Berlin, followed by some other cities in Brandenburg, for example Cottbus $\left(51.2^{\circ} \mathrm{N}, 14.19^{\circ} \mathrm{E}\right)$ and Frankfurt/Oder $\left(52.2^{\circ} \mathrm{N}, 14.33^{\circ} \mathrm{E}\right)$. The total area VOC emissions (upper panel, Fig. 6) show much higher amounts compared to the point emissions

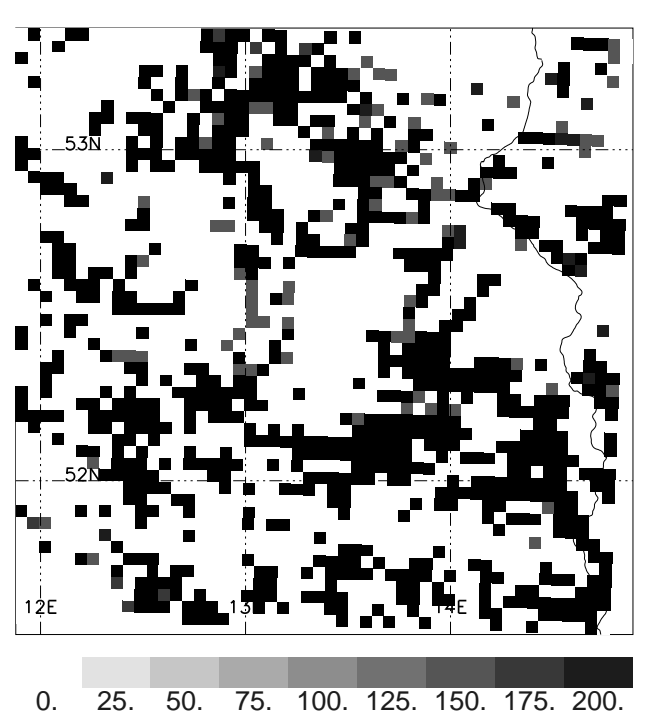

Fig. 7. Biogenic VOC emissions at 14:00 UTC on 23 July in $\mathrm{ppb}_{\mathrm{V}} \mathrm{C}$ per hour.

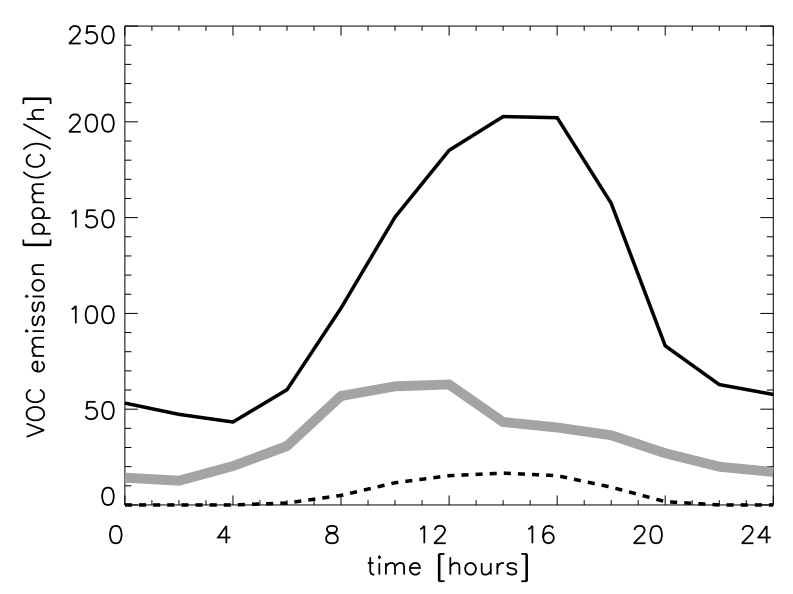

Fig. 8. Anthropogenically (grey line) and biogenically (black line) emitted hydrocarbons as a function of time of the day (23 July 1994). The isoprene emissions are plotted separately (black dashed line) but they are already included in the biogenic amounts. The emissions are sampled over the whole domain and shown in units of $p p b C$ per hour.

(lower panel).

\section{Biogenic Emission}

The natural emissions of biogenic VOCs, isoprene and monoterpenes, by vegetation are parameterized in GESIMA after Guenther et al. (1991, 1993). The areal distribution in Berlin-Brandenburg of biogenic VOCs at 14:00 UTC on 23 July is presented in Fig. 7. The diurnal variation is presented in Fig. 8. Biogenic hydrocarbons are emitted by forests only in the model formulation. Therefore, their horizontal distribution shows the areas in Brandenburg covered by forests. 
Emissionfluxes of about $200 \mathrm{ppb}_{\mathrm{v}} \mathrm{C} / \mathrm{h}$ are determined for coniferous forest and about $100 \mathrm{ppb}_{\mathrm{v}} \mathrm{C} / \mathrm{h}$ by deciduous forest.

To characterize the composition of air masses in the area of Berlin-Brandenburg the emitted VOC's on 23 July are shown in Fig. 8 subdivided into their biogenic and anthropogenic origin. Anthropogenically emitted hydrocarbons show a maximum between 08:00 and 12:00 UTC. This is a typical distribution for a Saturday where people work in the morning and rest in the afternoon. The largest contribution to the biogenic hydrocarbons comes from monoterpenes. Isoprene emissions are rather small. The area as well as the total amount of biogenic emissions clearly exceeds the anthropogenically emitted hydrocarbons.

\section{Ozone production}

In this chapter we investigate why the model system systematically underestimates ozone in the rural environment, whereas the urban concentrations correspond so well with the observations as shown in Bauer and Langmann (2002). The FLUMOB measurements include only ozone and $\mathrm{NO}_{2}$ observations particularly in near surface air. This is insufficient to understand and reconstruct the process of ozone formation. Photochemical ozone formation strongly depends on the presence of volatile organic compounds (VOC's). Due to the absence of further useful measurements a theoretical study will be carried out: In order to better understand ozone production in Berlin-Brandenburg $\mathrm{NO}_{\mathrm{x}}$-sensitive and VOC-sensitive regimes are classified after Sillman (1999) and Sillman et al. (1990): Ozone production in the planetary boundary layer is initialized by photolysis of $\mathrm{NO}_{2}$ (Eq. 1) followed by the rapid recombination of atomic oxygen $(\mathrm{O})$ with molecular oxygen $\left(\mathrm{O}_{2}\right)$. Usually this reaction is counterbalanced by the reaction of NO with ozone Eq. (2).

$\mathrm{NO}_{2} \stackrel{h v}{\longrightarrow} \mathrm{NO}+\mathrm{O}$.

$\mathrm{NO}+\mathrm{O}_{3} \longrightarrow \mathrm{NO}_{2}+\mathrm{O}_{2}$

But the $\mathrm{NO}_{\mathrm{x}}$-chemistry alone does not explain ozone production. The chemical process of ozone formation occurs via reaction sequences involving VOC and $\mathrm{NO}_{\mathrm{x}}$. Reactions transforming $\mathrm{NO}$ back to $\mathrm{NO}_{2}$ without consuming ozone are important, so that $\mathrm{NO}_{\mathrm{x}}$ acts as a catalyst Eq. (2). These reaction sequences are almost always initiated by reactions between hydrocarbons $(\mathrm{RH})$ and $\mathrm{OH}$ :

$$
\begin{aligned}
& \mathrm{RH}+\mathrm{OH} \cdot+\mathrm{O}_{2} \longrightarrow \mathrm{RO}_{2} \cdot+\mathrm{H}_{2} \mathrm{O} \\
& \mathrm{RO}_{2} \cdot+\mathrm{NO} \longrightarrow \mathrm{RO} \cdot+\mathrm{NO}_{2} \\
& \mathrm{HO}_{2} \cdot+\mathrm{NO} \longrightarrow \mathrm{OH} \cdot+\mathrm{NO}_{2}
\end{aligned}
$$

Reactions (4) and (5) convert $\mathrm{NO}$ back to $\mathrm{NO}_{2}$ and result in the formation of ozone when followed by reaction (1). hydrocarbons and intermediate compounds (VOC). In urban or polluted atmospheres reaction (4) and (5) represent the dominant pathways for $\mathrm{HO}_{2}$ and $\mathrm{RO}_{2}$ radicals. In this case the rate of ozone production is controlled by the availability of odd hydrogen radicals (defined as the sum of $\mathrm{OH}, \mathrm{HO}_{2}$ and $\mathrm{RO}_{2}$ ). Odd hydrogen radicals are produced by photolysis of ozone, formaldehyde and other intermediate organics:

$\mathrm{O}_{3}+\mathrm{H}_{2} \mathrm{O} \stackrel{h v}{\longrightarrow} 2 \mathrm{OH} \cdot+\mathrm{O}_{2}$

$\mathrm{HCHO}+2 \mathrm{O}_{2} \stackrel{h v}{\longrightarrow} 2 \mathrm{HO}_{2} \cdot+\mathrm{CO}$

They are removed by reactions that produce peroxide and nitric acid:

$$
\begin{aligned}
& \mathrm{HO}_{2} \cdot+\mathrm{HO}_{2} \cdot \longrightarrow \mathrm{H}_{2} \mathrm{O}_{2}+\mathrm{O}_{2} \\
& \mathrm{RO}_{2} \cdot+\mathrm{HO}_{2} \cdot \longrightarrow \mathrm{ROOH}+\mathrm{O}_{2} \\
& \mathrm{OH} \cdot+\mathrm{NO}_{2} \longrightarrow \mathrm{HNO}_{3}
\end{aligned}
$$

In order to better understand ozone production $\mathrm{NO}_{\mathrm{x}}$-sensitive and VOC-sensitive regimes are introduced. The split into these regimes is determined by the importance of the peroxide- and nitric-acid-formation reactions. When nitric acid represents the dominant sink of odd hydrogen, then the concentration of $\mathrm{OH}$ is determined by the equilibrium between reactions (6) and (10). In this case $\mathrm{OH}$ decreases with increasing $\mathrm{NO}_{\mathrm{x}}$ and either remains constant or increases due to the impact of reaction (7) with increasing VOC. In the VOC-sensitive regime the rate of ozone formation is controlled by the hydrocarbon-OH reaction (3) and increases with increasing VOC and decreases with increasing $\mathrm{NO}_{\mathrm{x}}$. In the $\mathrm{NO}_{\mathrm{x}}$-sensitive regime peroxides represent the dominant sink for odd hydrogen, the sum $\mathrm{HO}_{2}+\mathrm{RO}_{2}$ is relatively insensitive to changes in $\mathrm{NO}_{\mathrm{x}}$ or VOC. The rate of ozone formation increases with increasing $\mathrm{NO}_{\mathrm{x}}$ and is largely unaffected by VOC. We also classify an intermediate area (see Fig. 10) where ozone production is as well $\mathrm{NO}_{\mathrm{x}}$-sensitive as VOC-sensitive.

The relation between the VOC and $\mathrm{NO}_{\mathrm{x}}$ emissions in the total domain of Berlin-Brandenburg and their potential relation to ozone formation is illustrated in Fig. 10. This plot shows the potential ozone production as a function of $\mathrm{NO}_{\mathrm{x}}$ and VOC emission rates and is comparable to the ozone isopleth illustration (Fig. 9). In Fig. 10 the $\mathrm{NO}_{\mathrm{x}}$-sensitive and VOC-sensitive regimes are marked. The numbers represent the time of the day for the displayed data set. Note that the Berlin-Brandenburg area is $\mathrm{NO}_{\mathrm{x}}$-saturated. In the morning hours the area is definitely VOC-sensitive.

At noon and during the afternoon hours the system is in an intermediate state where it is VOC-sensitive as well as $\mathrm{NO}_{\mathrm{x}}$ sensitive. To get a more detailed understanding about the $\mathrm{O}_{3}-\mathrm{VOC}-\mathrm{NO}_{\mathrm{x}}$ regimes during this day in Brandenburg the VOC and $\mathrm{NO}_{\mathrm{x}}$ emissions will be divided into three groups. One group (total) as already discussed, represents the conditions in the whole model domain. The second ground (city) 


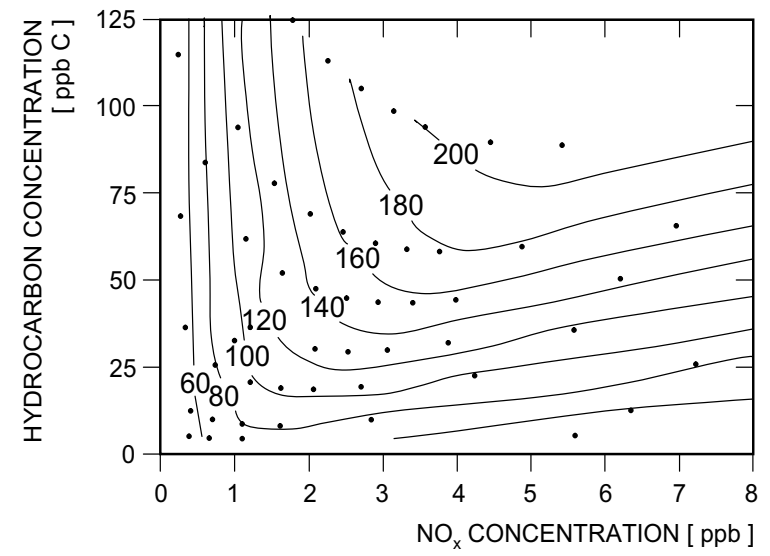

Fig. 9. Ozone in $\mathrm{ppb}_{\mathrm{v}}$ as function of the concentrations of $\mathrm{NO}_{\mathrm{x}}$ and VOC after Sillman et al. (1990). The dots refer to the simulations Sillman has done to calculate this figure.

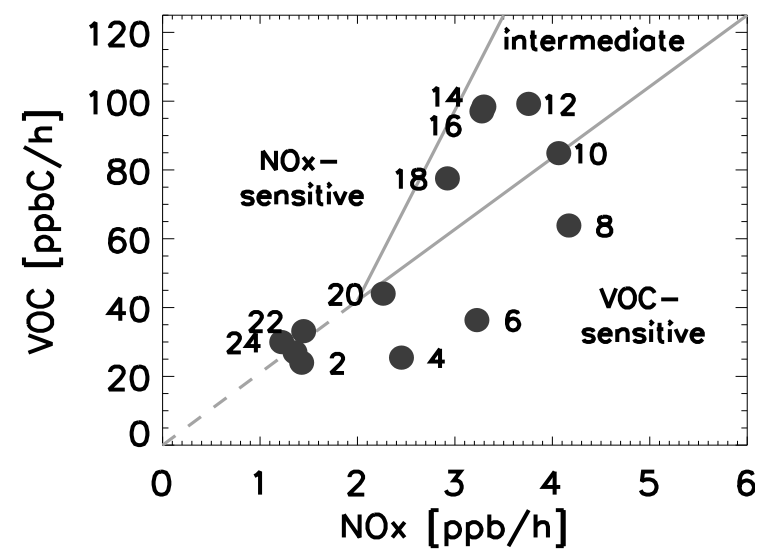

Fig. 10. Total emissions of VOC versus $\mathrm{NO}_{\mathrm{x}}$. Emissions of the total domain are shown. The numbers mark the time of the day. The lines separate the VOC- and $\mathrm{NO}_{\mathrm{x}}$-sensitive areas for ozone production.

represents urban conditions. These emission data sets are averaged over an area of $50 \times 50 \mathrm{~km}^{2}$ covering Berlin. Rural conditions are represented by the last group (rural) where the emission data sets are averaged over an area of $50 \times 50 \mathrm{~km}^{2}$ in the rural south-east of the domain. Figure 11 shows the diurnal emission cycle of these three groups scaled to the area of one grid box, e.g. $16 \mathrm{~km}^{2}$. The total and the rural emitted VOC's show quite similar magnitude and diurnal cycle. The largest fraction of VOC is of biogenic origin. Therefore, a rural character dominates throughout the model area. The city emissions show an inverse picture. Here the VOC's are dominated by anthropogenically emitted VOC's. The $\mathrm{NO}_{\mathrm{x}}$ emissions of these three groups are shown in the lower right panel of Fig. 11. Maximum $\mathrm{NO}_{\mathrm{x}}$ emissions are released in the city. The $\mathrm{NO}_{\mathrm{x}}$ emissions in the total domain show a more rural character.
A plot including all three groups of emission areas as discussed in this section is presented in Fig. 12. Only data during day time, when photochemistry is active between 06:00 and 20:00 UTC, are included in that picture. The black bullets show the VOC - $\mathrm{NO}_{\mathrm{x}}$ correlation of the total domain, as presented in Fig. 10. The grey squares show the correlation of city emissions and the grey stars the VOC - $\mathrm{NO}_{\mathrm{x}}$ correlation of rural emissions. The city area is completely $\mathrm{NO}_{\mathrm{x}}$ saturated. Urban ozone formation is only dependent on the availability of VOC. The rural area is rather VOC-saturated. Increasing $\mathrm{NO}_{\mathrm{x}}$ as well as VOC concentrations will increase ozone formation in the rural environment.

\subsection{Discussion}

This analysis demonstrates that ozone formation in the total domain of Berlin-Brandenburg and especially in the city region is VOC-sensitive. Increasing VOC concentrations will lead to additional ozone production. In the rural region, where the model evaluation (Bauer and Langmann, 2002) detected a systematically underprediction of ozone, the VOC$\mathrm{NO}_{\mathrm{x}}$ regime study show a sensitivity to $\mathrm{NO}_{\mathrm{x}}$ as well as to the VOC concentrations. These rural ozone formation process is still sensitive to the VOC concentrations especially in the morning hours. This presumption is confirmed by a sensitivity test with the REMO model, where biogenic emissions have been doubled and an ozone increase up to $10 \mathrm{ppb}_{\mathrm{v}}$ have been simulated even in rural areas.

However, the major part of the VOCs which are emitted in Berlin-Brandenburg are of biogenic origin. Therefore it is concluded that emissions of biogenic hydrocarbons, e.g. isoprene and monoterpene, are underestimated by the model. Unfortunately no useful VOC measurements exist for this period but measurements (Winkler et al., 2002) carried out in Berlin-Brandenburg during the field experiment BERLIOZ in summer 1998 strongly support the assumption presented here. It was found that the composition of VOCs in Brandenburg is dominated by about $80 \%$ by biogenic emissions. This study shows the great importance of biogenic VOC measurements when analysing ozone formation.

Nevertheless, the atmospheric composition is not exclusively characterized by directly emitted ozone precursors also the history of the air masses, the chemistry of the previous days, and the advected pollutants influence air pollution in Berlin-Brandenburg. Thus the simulation of the coarser model need to be included in the analysis.

\section{Influence of large scale conditions}

\subsection{Results of the REMO simulation}

The importance of trace species concentrations at the lateral boundaries of the GESIMA domain is analysed in this section. Especially longer living species like ozone, $\mathrm{CO}$ and 

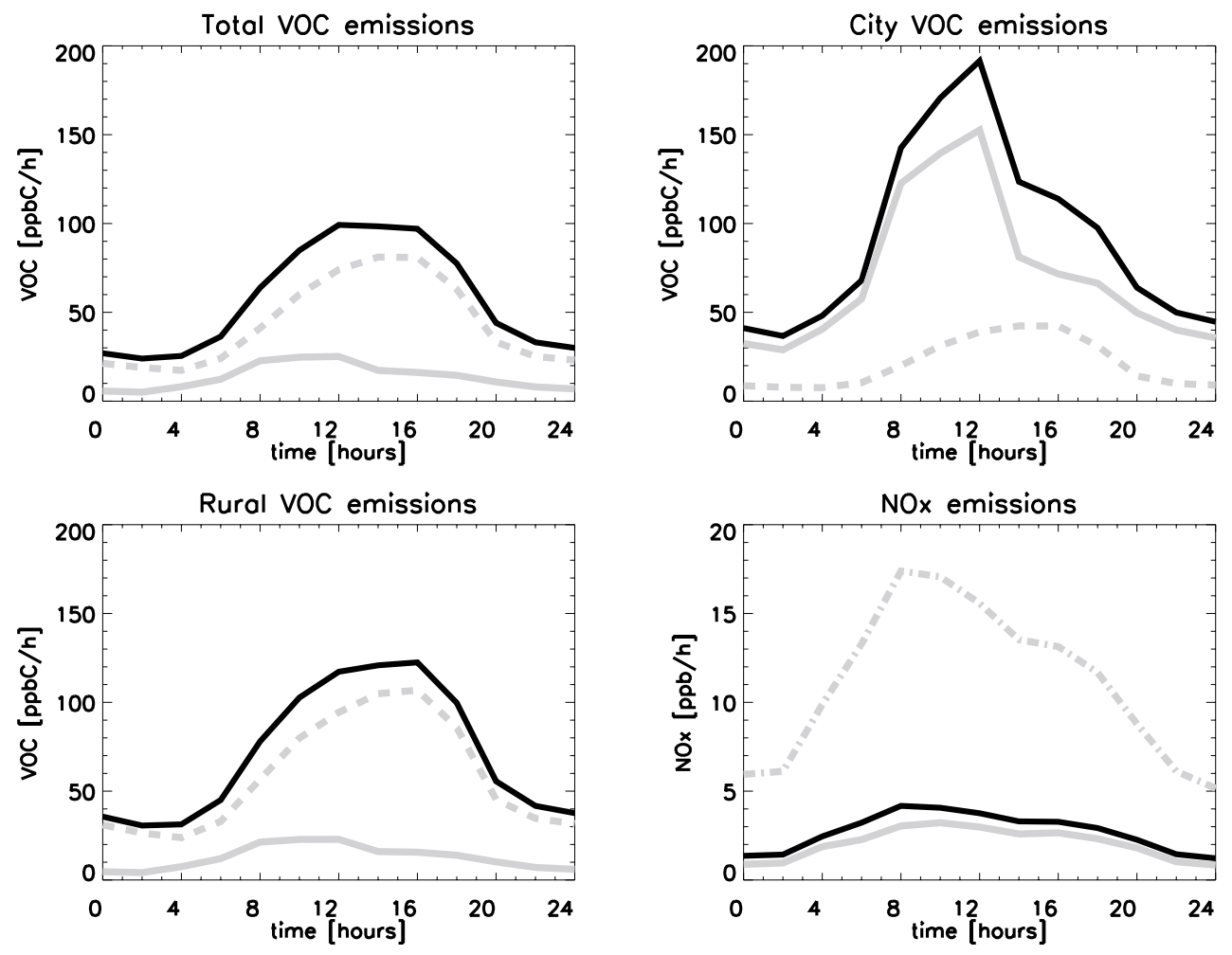

Fig. 11. Surface emissions as released in Berlin-Brandenburg on 23 July 1994. Biogenically (grey dashed line), anthropogenically (grey solid line), and the sum of both (black solid line). The upper left panel shows the emissions in the whole model domain, the upper right panel for the city domain and the lower left panel for the rural area. $\mathrm{NO}_{\mathrm{x}}$ emissions for the three groups total (black solid line), city (slash dot line), and rural (grey solid line) are shown in the lower right panel. The emissions are shown in $p p b / h$ scaled to the size of one grid box, e.g $16 \mathrm{~km}^{2}$.

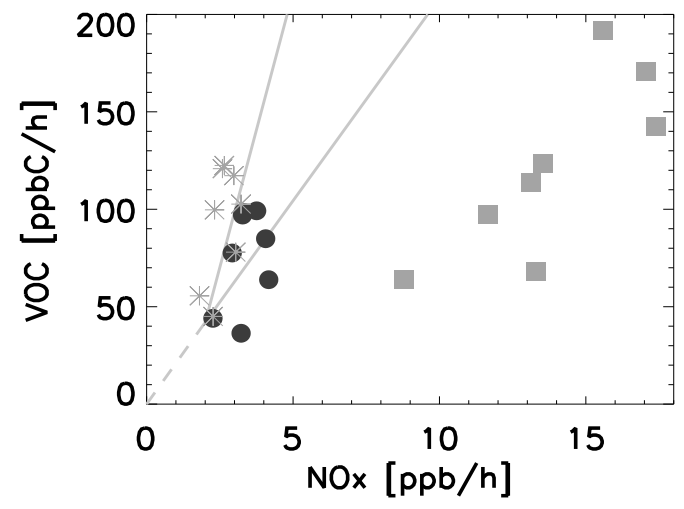

Fig. 12. Total emissions of VOC versus $\mathrm{NO}_{\mathrm{x}}$ in $\mathrm{ppb}_{\mathrm{v}}$ per hour and grid box area. Emissions representing the total domain (filled circles) and for rural (grey stars) and urban (grey squares) conditions are shown. The lines separate the VOC- and $\mathrm{NO}_{\mathrm{x}}$-sensitive areas.

$\mathrm{NO}_{y}$ or for example $\mathrm{SO}_{2}, \mathrm{CO}_{2}$ for climate studies, are sensitive to their horizontal and vertical distribution at the lateral boundaries (Brost, 1988; Langmann and Bauer, 2002).
The vertical distribution of ozone is also of great importance. Most trace gas species show maximum concentrations close to the Earth's surface which decrease with height. Contrarily, ozone is present in the whole troposphere with relatively high mixing ratios. Thus, the lifetime and distribution of ozone is also dependent on the larger scale conditions when investigating the processes of pollutant formation in Brandenburg. Therefore also the results of the regional model simulation will be discussed. Figure 13 shows measured and modelled near surface ozone concentrations of the REMO $1 / 6^{\circ}$ simulation at 15:00 UTC. During episode I (23 July; Fig.13, left panel) the air masses near the surface are advected mainly from the east to Germany and especially to Brandenburg. The near surface ozone concentrations increase from episode I to episode II (26 July; Fig.13, right panel) by about $20 \mathrm{ppb}_{\mathrm{v}}$ in Brandenburg. The comparison made here is for afternoon concentrations at 15:00 UTC. At noon the model shows better reproduction of observed ozone concentrations. In the afternoon and evening hours ozone underprediction increases. The general comparison between modelled and observed concentrations reveals that the observations show concentrations about $10 \mathrm{ppb}_{\mathrm{v}}$ higher. Al- 


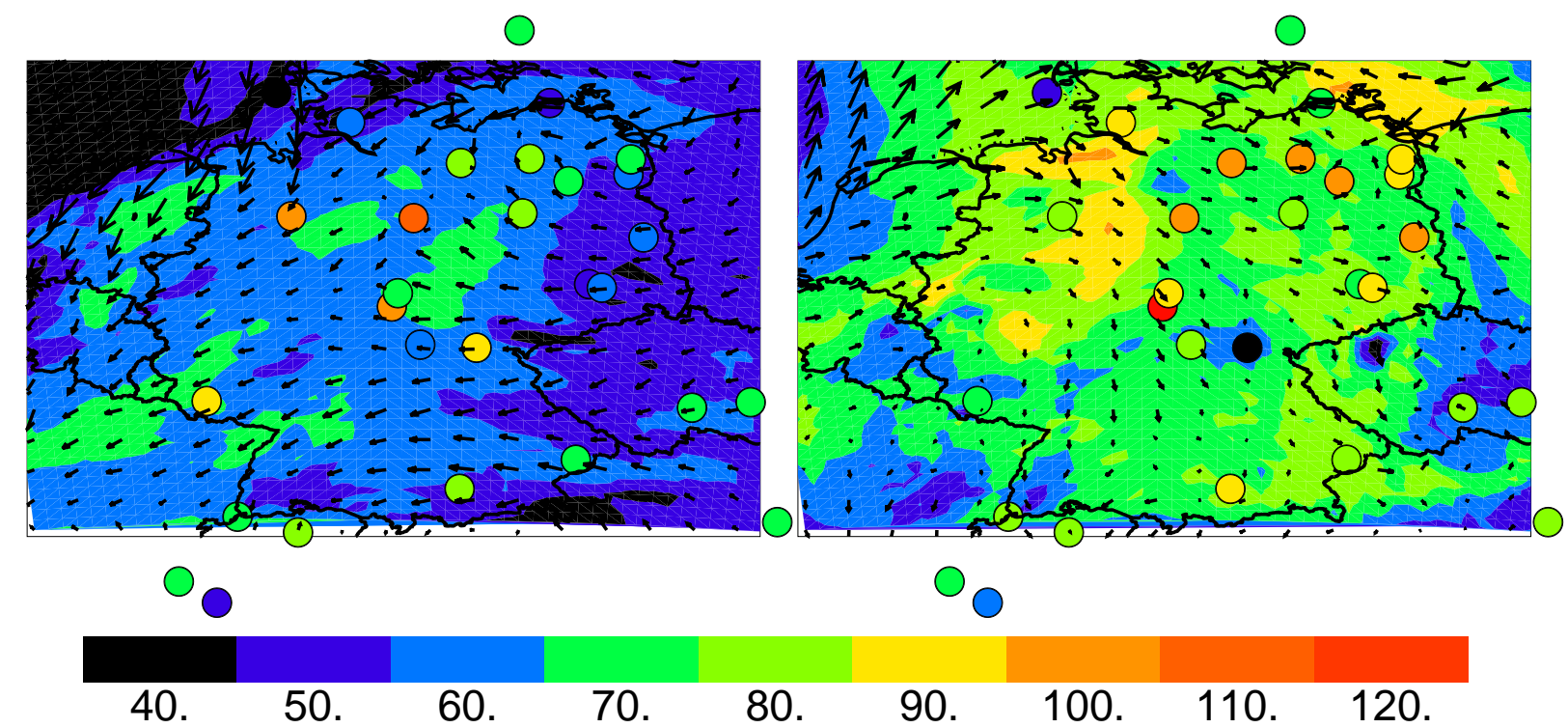

Fig. 13. Near surface ozone concentrations in $\mathrm{ppb}_{\mathrm{v}}$ as simulated by the REMO $1 / 6^{\circ}$ model for 23 July (left) and 26 (right panel) at $15: 00 \mathrm{UTC}$, respectively. The circles show observations. The arrows indicate the wind direction at $10 \mathrm{~m}$ altitude.
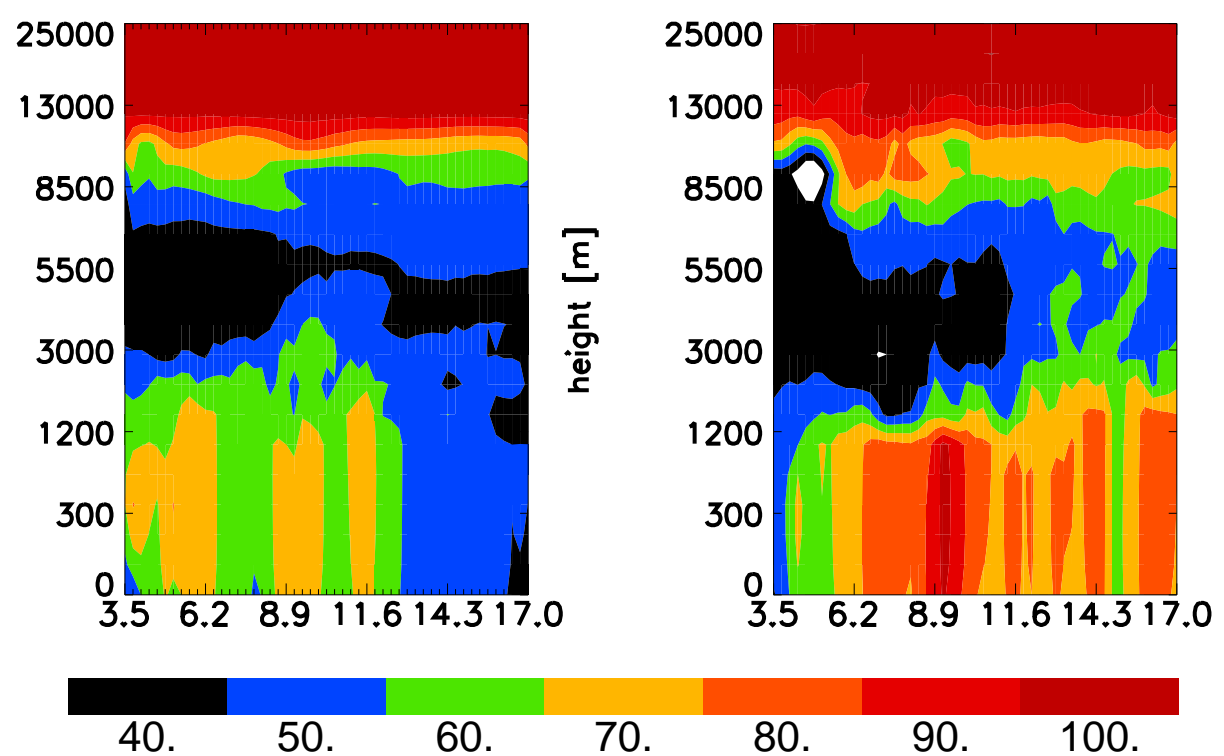

Fig. 14. Vertical distribution of ozone as simulated by REMO $1 / 6^{\circ}$ along $52.22^{\circ} \mathrm{N}$ latitude at 15:00 UTC on $23 \mathrm{July}$ (left panel) and 26 July (right panel). The numbers at the abscissa denote longitudes. The concentrations are shown in $\mathrm{ppb}_{\mathrm{v}}$.

though ozone concentrations are slightly underpredicted the model performance is reasonable for the near surface concentrations.

Figure 14 presents the simulated vertical ozone distribution along $52.22^{\circ} \mathrm{N}$ latitude on the $23 \mathrm{rd}$ and the 26th at 15:00 UTC. In the simulation ozone increases mostly in the planetary boundary layer, below $3000 \mathrm{~m}$. In the free troposphere, between 3000 and $10000 \mathrm{~m}$, ozone increases only slightly in the eastern model area and even decreases in the west.

The model evaluation (Bauer and Langmann, 2002) demonstrated that ozone is dramatically underpredicted in the free troposphere. An example is given in Fig. 15 where an ozone balloon sounding (dotted line) is compared with the REMO ozone profile (grey solid line) on 23 July at 16:00 UTC at Lindeberg. The Figure shows that ozone is underestimated by about $20 \mathrm{ppb}_{\mathrm{v}}$ in the lower and up to $50 \mathrm{ppb}_{\mathrm{v}}$ in the upper troposphere. These discrepancies were 


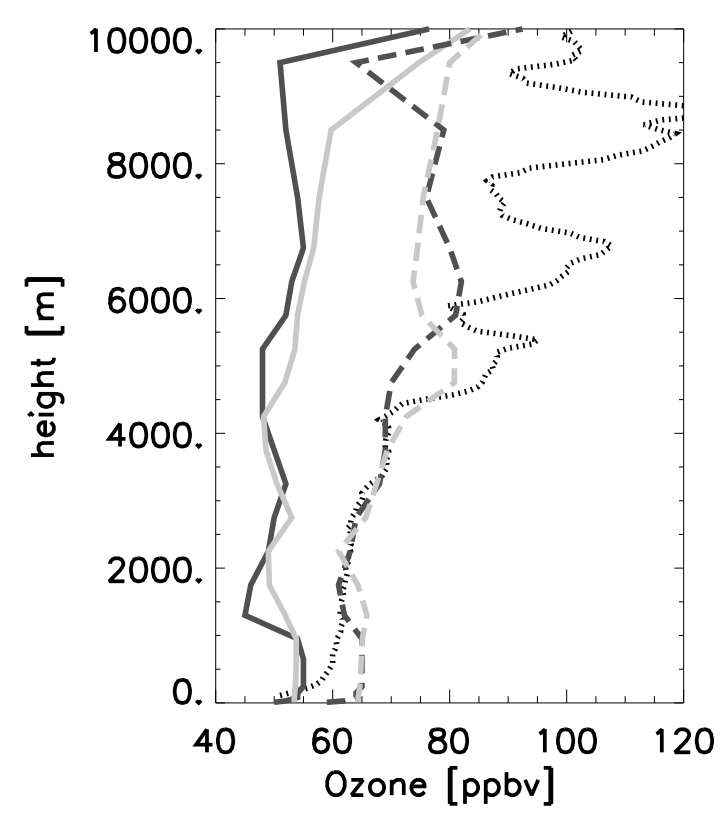

Fig. 15. Vertical profiles at station Lindenberg on 23 July launched at 16:00 UTC. The observations (black dots) are shown together with the REMO (grey solid), GESIMA (black solid) and REMOGEOS (grey dashed), GESIMA-GEOS (black dashed) profiles.

found in all three ozone soundings that have been carried out during FLUMOB. REMO simulates nearly time constant free tropospheric concentrations of about $50 \mathrm{ppb}_{\mathrm{v}}$ during the episode whereas the measured concentrations increased from episode I to II. To explain the observed high ozone concentrations in the free troposphere backward trajectories, calculated by the German Weather Service, are analysed. Backward trajectories give information about the pathway of air masses at different pressure levels. The trajectories for the air masses reaching Lindenberg on 26 July (episode II) are shown in Fig. 16.

The backward trajectories show that at about $700 \mathrm{hPa}$ air masses from south and south-west Germany are advected to Lindenberg. Following that trajectory the air masses pass highly polluted areas and ozone could have accumulated day by day in the lower troposphere. Above the planetary boundary layer the observed ozone concentrations originate from the Atlantic ocean four days prior to their arrival in Lindenberg. It is assumed that the observed unusually high mixing ratios of about $100 \mathrm{ppb}_{\mathrm{v}}$ is the result of mixing of long range transported upper level ozone and upward transported ozone from the planetary boundary layer, formed and accumulated during the summer smog event.

Because of the lack of measurements it is difficult to evaluate the assumption that during this summer smog event Europe was additionally influenced by high amounts of long range transported ozone. However, it seems to be the most probable explanation for the large amounts of ozone in the free troposphere. Other ozone balloon soundings, Brussels and Hohenpeißenberg, support this theory. The shape of the European wide ozone soundings and the analysis of weather maps exclude also stratospheric ozone intrusion.

\subsubsection{Discussion}

At the lateral inflow boundaries of the coarsest European wide REMO simulation constant climatological conditions are assumed for the transported chemical species (Bauer and Langmann, 2002). For ozone a concentration of about $50 \mathrm{ppb}_{\mathrm{v}}$ is assumed in the free troposphere, increasing up to $100 \mathrm{ppb}_{\mathrm{v}}$ towards the tropopause. Figure 14 demonstrates that these concentrations stay more or less constant during the simulation in the free troposphere. The analysis of the REMO simulation can be summarized in two points:

- The near surface ozone concentrations are slightly underpredicted especially in the afternoon hours. This underestimation may also be caused by an underestimation of the biogenic emissions as analysed for the GESIMA simulation. This finding is supported by a sensitivity study, carried out with the REMO model, where increased biogenic emissions result in an overall increase of near surface ozone concentrations. Additionally it should be noted that the REMO domains includes some countries which deliver incomplete emission information so that uncertainties in European wide anthropogenic emission inventories increase.

- Ozone is underestimated up to $50 \mathrm{ppb}_{\mathrm{v}}$ in the free troposphere. This problem can only be solved with more frequent observations of the three dimensional structure of the chemical state of the atmosphere. This information is not only important as lateral boundary condition but also for model initialization.

The importance and the influence of the vertical ozone distribution in the GESIMA simulation will be discussed in the following section.

\subsection{Influence of boundary conditions on the GESIMA sim- ulation}

To test the influence of the chemical lateral boundary conditions on the GESIMA simulation a sensitivity test was carried out: During one day of the simulation a constant amount of ozone is added to the vertical ozone distributions at the lateral inflow boundaries of the GESIMA domain. The results of the sensitivity run shows that in the free troposphere ozone concentrations depend mainly on the horizontal advection and in case of GESIMA on the lateral inflow boundary concentrations, thus on the REMO simulation.

The influence of the European wide REMO chemical boundary conditions on the mesoscale simulations have been studied in a more sophisticated experiment by Langmann et al. (2002), where the mesoscale model chain was nested 

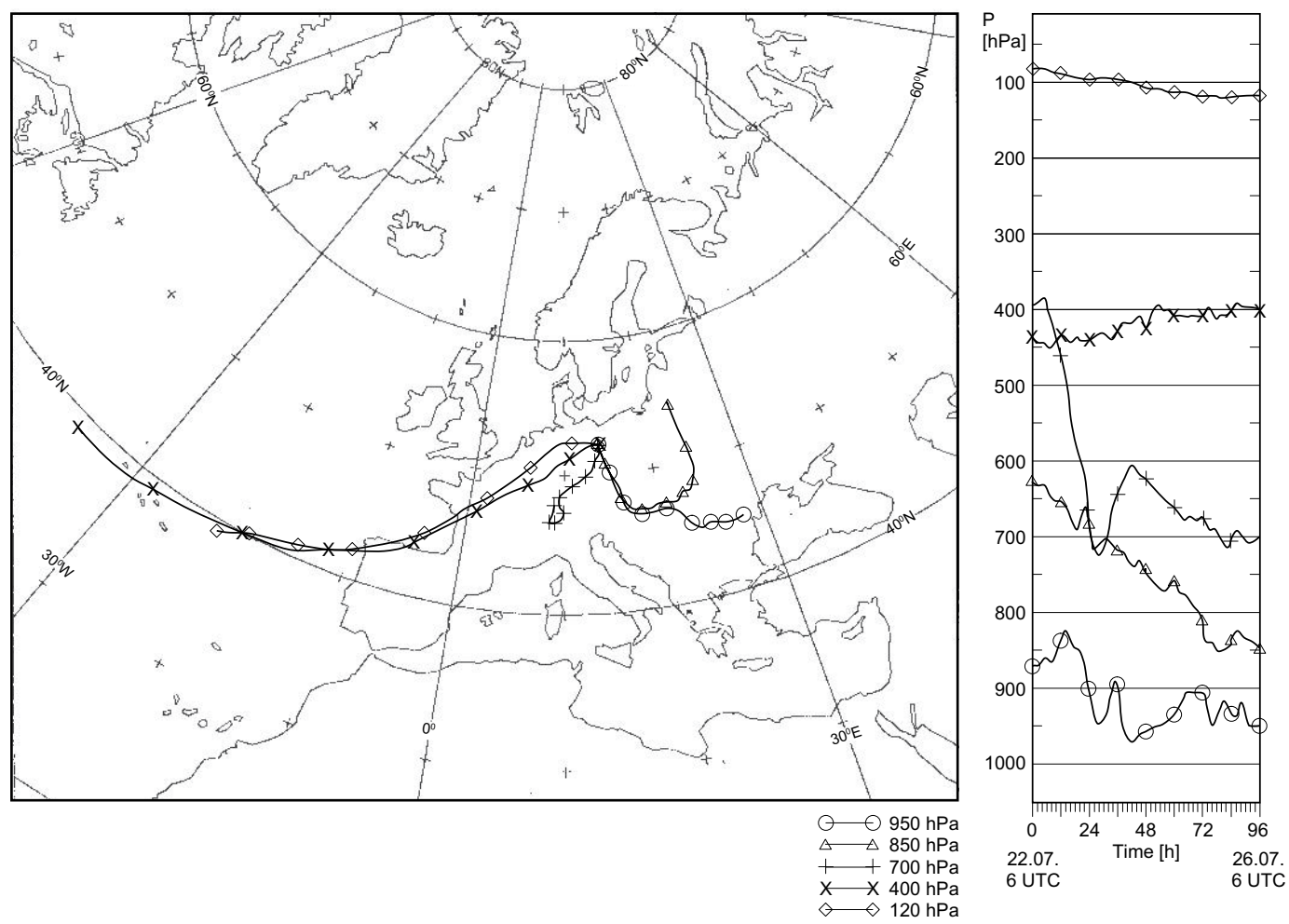

Fig. 16. Backward trajectories calculated for air masses reaching Lindenberg on 26 July.

into a global chemistry simulation. One result of this study is shown in Fig. 15: The ozone balloon sounding (dotted line) is compared to the REMO (grey solid line) and GESIMA (black solid line) simulated profiles (as discussed in this paper) and the profiles that result from the simulations that was nested to the global chemistry model, REMO-GEOS (grey dashed line) and GESIMA-GEOS (black dashed line). Two findings clearly can be seen: First, the REMO-GEOS simulation compares much better to the observation as it is discussed in detail in Langmann et al. (2002) where the need of global chemistry simulations for regional studies is stressed. Second, the GESIMA and REMO simulation stay very close to each other.

The two lateral boundary sensitivity experiments lead to the following conclusions concerning the GESIMA simulations:

- In the free troposphere, the ozone concentrations are strongly linked if not completely dependent to the ozone concentrations provided at the lateral model boundaries.

- Also in the planetary boundary layer the influence of the lateral boundary condition is strong: The ozone in the upper boundary level varies linearly to the amount of ozone which is provided at the lateral inflow boundaries.

- Even at the earth surface the ozone concentrations are affected by the lateral boundary due to the vertical mix- ing of ozone from higher levels to the surface (Langmann et al., 2002).

\section{Summary and conclusions}

The aim of the FLUMOB project was to measure the threedimensional distribution of the concentrations of ozone and its precursors. The objective of the FLUMOB project was to increase the understanding of the ozone formation processes in the urban polluted atmosphere of Berlin and its rural environment and to create suitable emission control strategies for ozone reduction.

(1) The two phases of FLUMOB

The FLUMOB period can be divided in two phases. They were induced by the meteorological conditions which lead to advection of relatively clean air masses from easterly directions during the first days (first phase of FLUMOB) and to transport of polluted air masses to Brandenburg coming from south eastern directions during the following days (second phase of FLUMOB). During phase one, the air pollutants in Berlin-Brandenburg were mainly formed by local emitted precursors. Enhanced pollutant concentrations were found in the downwind direction of the strongest emission sources. During phase two, an increase of ozone and further air pollutants were observed in the entire domain. Additionally to local production, aged polluted air masses were transported 
to Brandenburg, originating from South Germany. Furthermore, the investigated domain was influenced by increased ozone concentrations in the free troposphere which, due to vertical mixing, also influenced the surface concentrations.

(2) Dominance of biogenic hydrocarbons

The simulates composition of hydrocarbons in the modeled domain of Berlin-Brandenburg during the FLUMOB episode was made up by about $70-80 \%$ of biogenically emitted hydrocarbons, i.e. monoterpenes and isoprene, and by about $20-30 \%$ of anthropogenically emitted hydrocarbons. Thus, natural emissions released by trees in the widely forested areas of Brandenburg dominate over anthropogenic emissions. This is of special importance for the process of ozone formation in the investigated area because ozone production during FLUMOB was hydrocarbon limited so that their availability define the potential for ozone production and the peak concentrations.

This result is of fundamental importance for the FLUMOB project because the dominant role of biogenic hydrocarbons was completely underestimated. Measurements of hydrocarbons emitted by vegetation are complicated, because trees emit different types of hydrocarbons and the emission rates are very sensitive to temperature and irradiation. Especially monoterpene emissions are known to increase exponentially at high temperature. To make an accurate estimate of the flux of various compounds from a given region requires a detailed knowledge of vegetation species composition and the emission characteristics. With respect to the objectives of FLUMOB, i.e. the study of ozone reduction strategies, the important role of the hydrocarbons has to be taken into account. This would possibly lead to the requirement of considerably stronger $\mathrm{NO}_{\mathrm{x}}$ emission reduction strategies (Roselle and Schere, 1995; Chameides et al., 1992) to reduce the occurrence of ozone episodes in this region.

As this conclusion was not drawn by previous studies of the FLUMOB project, the subsequent ozone measurement campaign in Berlin-Brandenburg, BERLIOZ (Becker, 2000; Andersson and Steinhagen, 2000), carried out in summer 1998, did not focus on biogenic hydrocarbons. However, the measurements made during BERLIOZ confirm the conclusions of this paper concerning the composition of hydrocarbons in the Berlin-Brandenburg area during summer (Becker, 2000; Winkler et al., 2002).

(3) Increased ozone concentrations in the free troposphere In spite of the stagnant high pressure weather conditions during FLUMOB, Brandenburg was influenced by long range transported ozone concentrations. Unusually high ozone concentrations were measured by the few ozone balloon soundings. In contrast to previous analysis, this investigation showed that the high ozone concentrations in the free troposphere must originate from outside of Europe. Due to vertical mixing process these high concentrations influenced the near surface concentrations during the second phase of FLUMOB. The influence of upper level ozone on near surface concentrations was also monitored during the BERLIOZ experiment.
In contrast to the FLUMOB situation, the BERLIOZ case was even more influenced by transport processes. Therefore, observations of long lived trace gases, e.g. ozone, must include three-dimensional measurements especially when the processes of local ozone formation and distribution are investigated.

\section{(4) Sensitivity to lateral boundary conditions}

Ozone was dramatically underestimated by the model system in the free troposphere. The sensitivity study figured out that above the planetary boundary layer the amount of simulated ozone by GESIMA is completely dependent on the concentrations given to its lateral boundaries. Certainly, this result was expected and the lacking ozone in the free troposphere of GESIMA must be addressed to deficiencies in the regional model. The analysis of backward trajectories led to the assumption that the unusually high concentrations of upper tropospheric ozone originate from outside of Europe. Even the European wide simulation was not able to rebuild this situation because climatological conditions were assumed for the concentrations of the transported species at the lateral boundaries. Therefore global information about the three dimensional distribution of longer living chemical trace gases are necessary for regional modelling (Langmann et al., 2002).

As the FLUMOB episode was characterized by the stagnant weather conditions the strong influence of large scale transported ozone is an important result. To increase the understanding of atmospheric chemistry in the investigated region a next step would be to further analyse the role of biogenic hydrocarbons in the urban polluted atmosphere. All conclusions were drawn on the basis of a theoretical study and could only be verified by ambient measurements focusing on natural emissions associated with high atmospheric temperatures and strong solar radiation. These measurements are also necessary to improve the knowledge about biogenic emissions and their inclusion into inventories. In respect to these results new emission control studies should be tested.

Acknowledgements. The authors acknowledge the very helpful support by Guy Brasseur and Lennard Bengtsson. This work was founded by the Tropospheric Research Program (TFS) of the German Ministry for Education, Science, Research and Technology (BMBF). We wish to thank Burckhard Wickert, IER Stuttgart, for providing the emission data sets.

\section{References}

Andersson, S. and Steinhagen, H.: Untersuchungen zur Dynamik der atmosphärischen Grenzschicht und von Vertikalverteilungen ausgewählter Spurenstoffe mit Hilfe von WindprofilerRadar/RASS und Fesselballonsondierungen zur Oxidantienbildung und Oxidationskapazität, Deutscher Wetterdienst, Met. Observatorium Lindenberg, 2000. 
Bauer, S. E. and Langmann, B.: An atmosphere - chemistry model on the meso- $\gamma$ scale: Model description and evaluation, Atmos. Environ., 36, 2187-2199, 2002.

Becker, K. H.: Förderschwerpunkt Troposphärenforschung 19962000, Kurzübersicht Leitthema 3: Prozeßstudien zur Oxidantienbildung und Oxidationskapazität, Bundesministerium für Bildung und Forschung, Institut für Physikalische Chemie, Bergische Universität GH Wuppertal, 2000.

Brost, R. A.: The sensitivity to input parameters of atmospheric concentrations simulated by a regional chemical-model, J. Geophys. Res., 93, 2371-2387, 1988.

Chameides, W. L., Fehsenfeld, F., Rodgers, M., Cardelino, C., Martinez, J., Parrish, D., Lonneman, W., Lawson, D. R., Rasmussen, R., Zimmerman, P., Greenberg, J., Middleton, P., and Wang, T.: Ozone precursor relationships in the ambient atmosphere, J. Geophys. Res, 97, 6037-6055, 1992.

Friedrich, R., Wickert, B., Blank, P., Emeis, S., Engewald, W., Hassel, D., Hoffmann, H., Michael, H., Obermeier, A., Schäfer, K., Schmitz, T., Sedlmaier, A., Stockhause, M., Theloke, J., and Weber, F. J.: Development of emission models and improvement of emission data for Germany, J. Atmos. Chem., 42, 179-206, 2002.

Guenther, A. B., Monson, R. K., and Fall, R.: Isoprene and monoterpene emission rate variability: Observations with eucalyptus and emission rate algorithm development, J. Geophys. Res., 96, 10 799-10 808, 1991.

Guenther, A. B., Zimmermann, P. K., Harley, P. C., Monson, R. K., and Fall, R.: Isoprene and monoterpene emission rate variability: Model evaluations and sensitivity analysis, J. Geophys. Res., 98, 12 609-12 617, 1993.

Langmann, B.: Numerical modelling of regional scale transport and photochemistry directly together with meteorological processes, Atmos. Environ., 34, 3585-3598, 2000.

Langmann, B. and Bauer, S. E.: On the importance of reliable initial and boundary concentrations of ozone for regional scale air pollution modelling, J. of Atm. Chem., 42, 71-90, 2002.

Langmann, B., Bauer, S. E., and Bey, I.: The influence of the global photochemical composition of the troposphere on European summer smog. Part I: Application of a global to mesoscale model chain, J. Geophys. Res., accepted, 2002.

Majewski, D.: The Europa Modell of the Deutscher Wetterdienst, Tech. Rep. 2, Seminar Proceedings ECMWF, pp. 114, 1991.

Roselle, S. J. and Schere, K. L.: Modeled response of photochemical oxidants to systematic reductions on anthropogenic volatile organic compound and $\mathrm{NO}_{x}$ emissions, J. Geophys. Res., 100, 22 929-22 941, 1995.

Seinfeld, J. H. and Pandis, S. N.: Atmospheric Chemistry and Physics. From Air Pollution to Climate Change, John Wiley and Sons, Inc. New York, 1998.

Sillman, S.: The relation between ozone, $\mathrm{NO}_{x}$ and hydrocarbons in urban and polluted rural environments, Atmos. Environ., 33, 1821-1845, 1999.

Sillman, S., Logan, J. A., and Wofsy, S. C.: The sensitivity of ozone to nitrogen oxides and hydrocarbons in regional ozone episodes, J. Geophys. Res., 95, 1837-1851, 1990.

Stark, B., Abraham, H.-J., Lutz, P., Reichenbächer, M., Reimer, W., and Scherer, E.: Flugzeug- und Bodenmessungen von Ozon und Verläuferstoffen zur Abschätzung der Wirksamkeit von emissionsmindernden Maßnahmen im Großraum BerlinBrandenburg (FLuMOB-Projekt), Abschlußbericht im Auftrag der Senatverwaltung für Stadtentwicklung und Umweltschultz Berlin und des Ministeriums für Umwelt und Raumordnung des Landes Brandenburg, Berlin, 1995.

Stockwell, W. R., Middleton, P., and Chang, J. S.: The second generation regional acid deposition model chemical mechanism for regional air quality modeling, J. Geophys. Res., 95, $16343-$ $16367,1990$.

Walcek, C. J. and Taylor, G. R.: A theoretical method for computing vertical distributions of acidity and sulfate production within cumulus clouds, J. Atmos. Sci., 43, 339-355, 1986.

Winkler, J., Blank, P., Glaser, K., Habram, M., Jambert, C., Jaeschke, W., Konrad, S., Kurtenbach, R., Lenschow, P., Lörzer, J. C., Perros, P. E., Pesch, M., Prümke, H. J., Rappenglück, P., Schmitz, T., Slemr, F., Volz-Thomas, A., and Wickert, B.: Ground-based and airborne measurements of nonmethane hydrocarbons in BERLIOZ: Analysis and selected results, J. Atmos. Chem., 42, 465-492, 2002. 